\title{
Public Trust in Nonprofit Organizations (NPOs): Aggregation levels of NPO trust at stakeholder side and conceptual objects of trust at NPO side
}

\author{
Jurgen Willems ${ }^{1}$
}

\begin{abstract}
Public trust in nonprofit organizations (NPOs) is the extent that stakeholders consider nonprofit organizations reliable and truthful to what they do and communicate. Concretely, this means that stakeholders believe that nonprofits' acts conform to their goals, including that these nonprofit organizations do not produce profit for personal and/or private gains (Hansmann, 1987). The public aspect of public trust in nonprofit organizations focuses on the aggregated trust perceptions - or shared cognition from several relevant stakeholder groups, like beneficiaries, donors, funders, volunteers, employees, and collaboration partners, such as government agencies, businesses, and other nonprofit organizations. Hence, individual stakeholders can trust NPOs to a different extent, depending on various factors, such as their concrete stakeholder role towards the organization, earlier experiences, personal needs and preferences, and access to information about the nonprofit
\end{abstract}

organization (Becker et al., 2020). The aggregated concept of public trust in nonprofits is the extent to which these individual trust perceptions are shared within larger stakeholder groups.

However, aggregation at different levels is not possible on the side of the stakeholders alone. Also, on the nonprofit side, different conceptual elements about nonprofit organizations can be distinguished to clarify the different theoretical and practical perspectives on public trust in nonprofit organizations. These conceptual elements are (1) the general concept of nonprofits, (2) the nonprofit sector and/or networks of nonprofits, (3) nonprofit organizations, and (4) particular persons representing an NPO in concrete interactions with stakeholders (i.e. individual internal stakeholders). Figure 1 gives a conceptual representation of these different levels on the stakeholderside (left) and the different conceptual elements forming trust in nonprofits (right).

\footnotetext{
${ }^{1}$ Institute for Public Management \& Governance - Vienna University of Economics and Business Jurgen.willems@wu.ac.at; ORCID: https://orcid.org/0000-0002-4439-3948

This is a preprint version, uploaded to Open Science Framework (September, 2021).

Open access figure, for example for lectures, is available at: Willems, J. (2021): Public Trust in Nonprofit Organizations (NPOs): Aggregation levels of NPO trust at stakeholder side and conceptual objects of trust at NPO side. figshare. Figure. https://doi.org/10.6084/m9.figshare.16701973
} 


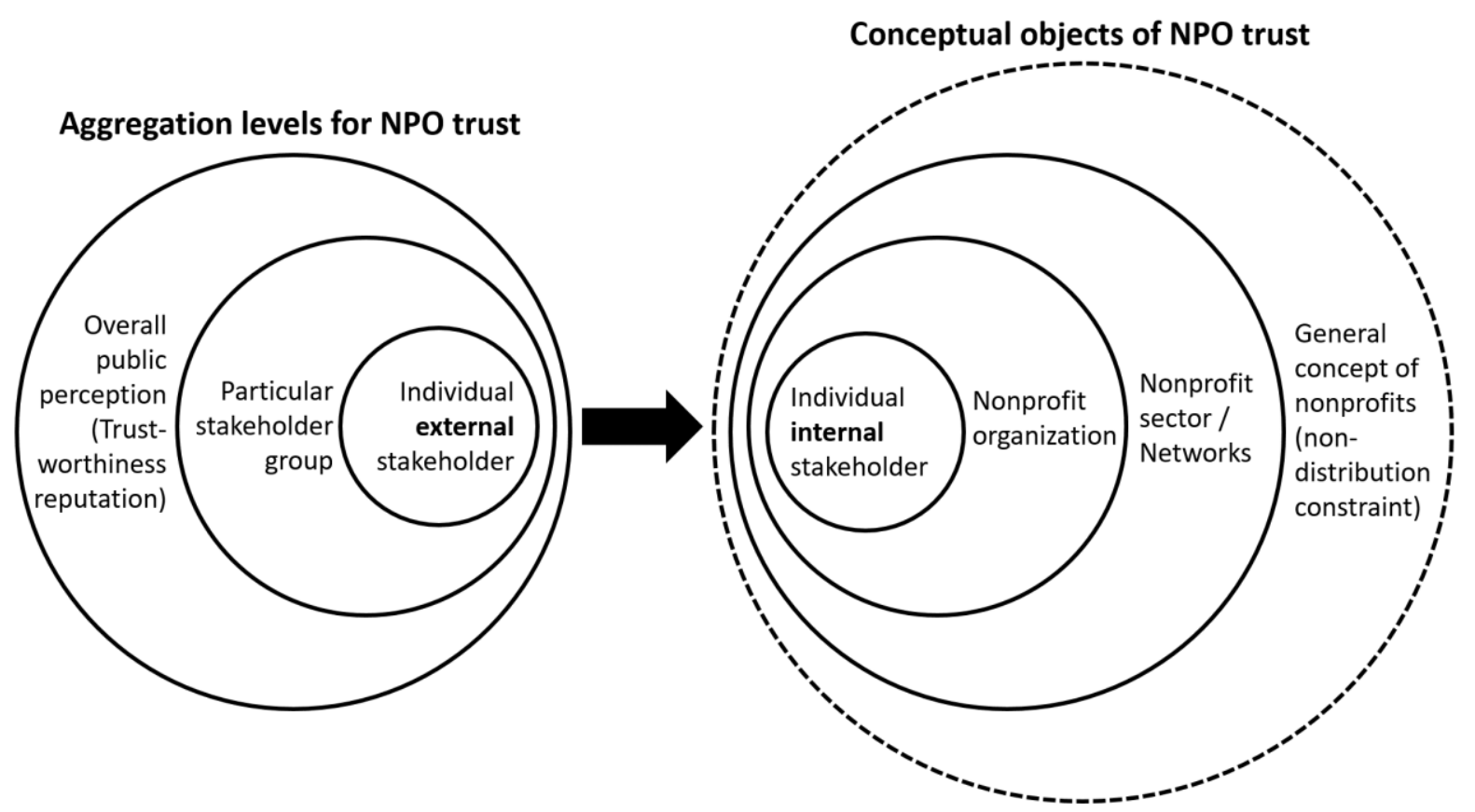

Figure 1: Aggregation levels of NPO trust at stakeholder side (left) and conceptual objects of trust at NPO side (right).

Depending on the different levels of aggregation (see Figure 1), trust in NPOs can have very different applications. Concretely, this means that NPO actions can focus on creating and improving trust on the different levels at the stakeholder side. Trust at each of these different levels relates to various relevant NPO concepts. For example, a single stakeholder trusting an organization might be more willing to give a concrete donation or recommendation about an organization. In contrast, trust at more aggregated levels can relate to organizational reputation and the legitimacy for an NPO to represent a stakeholder group in dealing with their needs.

Consistently, actions to create and maintain trust can also be taken at different levels at the NPO side. They can be particular, where a single person in an NPO acts and communicates reliably and truthfully. For example, the way fundraisers communicate and deal with donation money contains concrete elements that determine stakeholder trust in NPOs. Similarly, concrete communication by an NPO's manager or its board members can hugely influence the overall trust in NPOs.
On the organizational level, an NPO can formalize governance practices that induce organizational transparency and accountability, contributing to higher levels of trust for specific stakeholders and aggregated groups (Dethier et al., 2021).

Moreover, nonprofit organizations can also engage in collective action through networks with other NPOs, to signal overall reliability and truthfulness. Self-regulatory codes of conduct or benchmark studies are sector-level examples to build trust beyond the boundaries of single organizations (Appe, 2016). On the highest conceptual level, NPO trust is created by the unique nature of nonprofits. The non-distribution constraint, a defining element of nonprofit organizations (Hansmann, 1987), states that nonprofits do not distribute profits from their activities for personal gains to owners. Therefore, nonprofits have no formal owner structure like that of for-profit organizations. This lack of formal structure creates a situation where stakeholders would trust nonprofit organizations more than for-profit organizations, in particular for services where it is hard to assess the true quality and/or motivation of the people working for those organizations. This is 
relevant for organizational activities performed in mixed markets, meaning that these activities are simultaneously performed by for-profit, non-profit, and public organizations, like healthcare and education (Ben-Ner \& Van Hoomissen, 1991). Hence, the non-distribution constraint that defines nonprofit organizations is a trust-creating mechanism in itself.

Public trust in NPOs has received increasing attention in scientific and policy debates on NPO transparency and accountability, mainly because of some NPO scandals that received global attention. Although these scandals are very often caused by the behavior of a very select group of unreliable and untruthful individuals, the trust consequences are often evident for entire nonprofit organizations, networks, and the sector as a whole (Willems, 2016). Moreover, the required strategies to recover from the damage - in terms of trust breaches for stakeholders caused by such scandals - also require actions at the various NPO levels (individuals, organizations, networks, and the NPO sector as a whole). Against this background, managing trust has gained importance for practitioners as well as for NPO scholars. Nevertheless, the theoretical and empirical foundations to make solid and generalizable recommendations to keep trust high - or to recover effectively from scandals - have not yet fully matured. Thus, great opportunities still exist for nonprofits to collaborate with social science scholars to develop, test, and continuously improve guidelines for individual behaviors as well as practices at the organizational, network, and sector levels to increase and consolidate NPO trust. This would require (even more) the willingness of NPOs to engage in collaborations with scholars, while for scholars, it would mean striving for more practical impact with their scientific output.

\section{References and recommended reading}

Appe, S. (2016). NGO networks, the diffusion and adaptation of NGO managerialism, and NGO legitimacy in Latin America. Voluntas: International Journal of Voluntary and Nonprofit Organizations, 27, 187-208. DOI: https://doi.org/10.1007/s11266-015-9594-y

Becker, A., Boenigk, S., \& Willems, J. (2020). In nonprofits we trust? A large-scale study on the public's trust in nonprofit organizations. Journal of Nonprofit \& Public Sector Marketing, 32, 189-216. DOI: https://doi.org/10.1080/10495142.2019.1707744

Ben-Ner, A., \& Van Hoomissen, T. (1991). Nonprofit organizations in the mixed economy: A demand and supply analysis. Annals of Public and Cooperative Economics, 62(4), 519-549. DOI: https://doi.org/10.1111/j.1467-8292.1991.tb01366.x

Dethier, F., Delcourt, C., \& Willems, J. (2021). Transparency of nonprofit organizations: An integrative framework and research agenda. Journal of Philanthropy and Marketing. Published online before print. DOI: http://dx.doi.org/10.1002/nvsm.1725

Hansmann, H. (1987). Economic theories of nonprofit organizations. In W.W. Powell (Ed.), The nonprofit sector: A research handbook (pp. 27-42). Yale University Press.

Willems, J. (2016). Organizational crisis resistance: Examining leadership mental models of necessary practices to resist crises and the role of organizational context. Voluntas: International Journal of Voluntary and Nonprofit Organizations, 27(6), 2807-2832. DOI: https://doi.org/10.1007/s11266-016-9753-9

Willems, J. (2021): Public Trust in Nonprofit Organizations (NPOs): Aggregation levels of NPO trust at stakeholder side and conceptual objects of trust at NPO side. figshare. Figure. https://doi.org/10.6084/m9.figshare.16701973 